\title{
Myocardial perfusion reserve in spared myocardium: one more tessera of the complex mosaic of $L V$ remodelling after myocardial infarction
}

\author{
Raffaele Giubbini • Francesco Bertagna
}

Published online: 29 May 2013

(C) Springer-Verlag Berlin Heidelberg 2013

In their interesting paper, Juárez-Orozco and colleagues [1] analysed the relationship between left ventricular remodelling, infarct size and myocardial flow reserve in the spared myocardium and other clinical parameters in a group of patients with previous myocardial infarct. The infarct size was estimated by FDG PET, whereas the myocardial flow reserve in the spared myocardium was measured by ${ }^{13} \mathrm{~N}$-ammonia PET at rest and after dipyridamole vasodilation. They found that both infarct size and myocardial perfusion reserve were correlated with ejection fraction on follow-up imaging and that myocardial perfusion reserve had a stronger correlation with left ventricular ejection fraction than infarct size in a multivariate model. Interestingly, $39 \%$ of patients had single-vessel disease of the infarct related the coronary artery and that $78 \%$ had undergone a revascularization procedure (both PCI and $\mathrm{CABG}$ ) and, therefore it is reasonable to hypothesize that the spared myocardium was subtended by patent vessels in the majority of patients. Their findings suggest that, in patients with a prior history of myocardial infarction, left ventricular ejection fraction is not related just to infarct size but also to myocardial perfusion reserve in the spared myocardium. These are the observed findings and the next question that should be raised and investigated is: why?

In patients with coronary artery disease the myocardial blood flow after maximal vasodilation obtained by adenosine administration is abnormal in the majority of territories subtended by stenotic vessels [2]. In a study recently published in this journal, Zhang et al. [3] observed that in patients with ischaemic cardiomyopathies myocardial blood flow at rest was significantly reduced in both viable and nonviable regions, but that myocardial blood flow in remote regions was similar to that in the normal volunteers.

\section{R. Giubbini $(\bowtie) \cdot$ F. Bertagna}

Nuclear Medicine Department, University of Brescia,

Piazza Spedali Civili, 1,

25128 Brescia, Italy

e-mail: giubbini@med.unibs.it
Dipyridamole stress significantly increased myocardial blood flow in all regions. However, the flow response to the dipyridamole-induced vasodilation in remote myocardium of patients remained significantly below that in the normal population. Therefore, myocardial flow reserve in remote myocardium was significantly compromised in comparison to that in normal controls. Flow reserve values of vasodilated territories can be affected by levels of "resting" flow. The higher the resting flow the lower the myocardial perfusion reserve independently of the maximal flow reached under vasodilation. In healthy normal individuals, pharmacological vasodilation can increase resting absolute myocardial blood flow by four- to fivefold, with only modest, if any, changes in heart rate and arterial pressure.

Several factors including hypercholesterolaemia [4], smoking [5], diabetes mellitus [6] and hypertension [7] can produce endothelial dysfunction in the absence of significant stenoses of the epicardial arteries. Furthermore, coronary calcium content independently affects regional myocardial blood flow reserve [8]. In the population of Juárez-Orozco et al., hypercholesterolaemia was present in $42 \%$, smoking in $43 \%$, diabetes mellitus in $10 \%$ and hypertension in $36 \%$.

The regulation of endothelial reactivity is very complex and under the control of several mechanisms. The endothelium produces vasodilators, endothelium-derived relaxing factors, such as nitric oxide and prostacyclin. This results in smooth muscle relaxation and increased blood flow. Nitric oxide has a very short half-life according to its interaction with other free radicals. Nitric oxide release is triggered by products of thrombosis, platelet aggregation and increased shear stress with flow-mediated vasodilation. The endothelium also produces vasoconstrictors such as endothelin-1. In normal endothelium, vasodilator function rather than vasoconstriction is dominant in response to neurohumoral and mechanical stimuli. Endothelium-dependent vasodilation is predominant over direct smooth muscle constriction in normal 
arteries. Endothelin-1 has roles in vasoconstriction, stimulation of smooth muscle. cell proliferation, vascular remodelling and inflammatory cell adhesion. Oxidized LDL is a potent stimulus of endothelin-1 production [9].

In left ventricular remodelling the development of collateral vessels can play an important role. The coronary collateral system creates a dynamic network of interarterial vessels that can undergo both long-term and short-term adjustments that can modulate blood flow to the dependent myocardium. Long-term adjustments including recruitment and growth of collateral vessels in response to arterial occlusion are time-dependent and determine the maximum blood flow rates available to the collateral-dependent vascular bed during exercise. Mature coronary collateral vessels are responsive to vasodilators such as nitroglycerin and atrial natriuretic peptide, and to vasoconstrictors such as vasopressin, angiotensin II and the platelet products serotonin and thromboxane A2 [10]. During exercise, adrenergic activity and endothelium-derived nitric oxide and prostacyclin also exert vasodilator effects on coronary collateral vessels. Importantly, alterations in collateral vasomotor tone by exogenous vasopressin, inhibition of endogenous nitric oxide or prostacyclin production, or increasing local adenosine production can modify collateral conductance, thereby influencing the blood supply to the dependent myocardium [10].

The ultimate message of the study by Juárez-Orozco et al. [1] is that vasomotor activity in the resistance vessels of their study group (patients with previous myocardial infarction) is an expression of global as well as of regional controllers, depending on several factors which need to be further explored and reinforcing previous observations available as early as the early 1990s [11]. Several physiopathological mechanisms control the adaption of myocardium to the changed structural and functional state after myocardial infarction. The quantitative measurement of myocardial blood flow and blood flow reserve in spared myocardium may represent an important tessera in the understanding of the interactions among the pieces of the mosaic subtending left ventricular remodelling. Understanding the relationship among these complex phenomena and the potential of pharmacological intervention might lead to the possibility of limiting or to reversing left ventricular remodelling after myocardial infarction.

\section{References}

1. Juárez-Orozco LE, Glauche J, Alexanderson E, Zeebregts CJ, Boersma HH, Glaudemans AW, et al. Myocardial perfusion reserve in spared myocardium: correlation with infarct size and left ventricular ejection fraction. Eur J Nucl Med Mol Imaging. 2013. doi:10.1007/s00259-013-2394-y.

2. Hajjiri MM, Leavitt MB, Zheng H, Spooner AE, Fischman AJ, Gewirtz H. Comparison of positron emission tomography measurement of adenosine-stimulated absolute myocardial blood flow versus relative myocardial tracer content for physiological assessment of coronary artery stenosis severity and location. JACC Cardiovasc Imaging. 2009;2(6):751-8.

3. Zhang X, Schindler TH, Prior JO, Sayre J, Dahlbom M, Huang SC, et al. Blood flow, flow reserve, and glucose utilization in viable and nonviable myocardium in patients with ischemic cardiomyopathy. Eur J Nucl Med Mol Imaging. 2013;40(4):532-41.

4. Yokoyama I, Ohtake T, Momomura S, Nishikawa J, Sasaki Y, Omata M. Reduced coronary flow reserve in hypercholesterolemic patients without overt coronary stenosis. Circulation. 1996;94(12):3232-8

5. Valenta I, Dilsizian V, Quercioli A, Schelbert HR, Schindler TH. The influence of insulin resistance, obesity, and diabetes mellitus on vascular tone and myocardial blood flow. Curr Cardiol Rep. 2012;14(2):217-25.

6. Morita K, Tsukamoto T, Naya M, Noriyasu K, Inubushi M, Shiga $\mathrm{T}$, et al. Smoking cessation normalizes coronary endothelial vasomotor response assessed with $15 \mathrm{O}$-water and PET in healthy young smokers. J Nucl Med. 2006;47(12):1914-20.

7. Alexánderson $E$, Jácome R, Jiménez-Santos $M$, Ochoa JM, Romero E, Cabral MA, et al. Evaluation of the endothelial function in hypertensive patients with $13 \mathrm{~N}$-ammonia PET. J Nucl Cardiol. 2012;19(5):979-86.

8. Liga R, Marini C, Coceani M, Filidei E, Schlueter M, Bianchi M, et al. Structural abnormalities of the coronary arterial wall in addition to luminal narrowing affect myocardial blood flow reserve. J Nucl Med. 2011;52(11):1704-12.

9. Yoshinaga K, Manabe O, Tamaki N. Assessment of coronary endothelial function using PET. J Nucl Cardiol. 2011;18(3):486500 .

10. Duncker DJ, Bache RJ. Regulation of coronary blood flow during exercise. Physiol Rev. 2008;88:1009-86.

11. Sambuceti G, Marzullo P, Giorgetti A, Neglia D, Marzilli M, Salvadori $\mathrm{P}$, et al. Global alteration in perfusion response to increasing oxygen consumption in patients with single-vessel coronary artery disease. Circulation. 1994;90(4):1696-705. 